\section{Estudo \\ cabebate}

em Cestão

Planejamento
Revista Estudo \& Debate, Lajeado, v. 27, n. 3, 2020. ISSN 1983-036X DOI: http://dx.doi.org/10.22410/issn.1983-036X.v27i3a2020.2559

\title{
CONCENTRAÇÁO DOS EMPREGOS SETORIAIS NAS MICRORREGIÔES BRASILEIRAS: UMA ANÁLISE ENTRE GÊNEROS PARA OS ANOS DE 2002 A 2018, COM ÊNFASE NO MERCADO DE TRABALHO FEMININO
}

\author{
Luzia Aparecida Antunes ${ }^{1}$
}

\begin{abstract}
Resumo: A participação das mulheres no mercado de trabalho vem crescendo ao longo dos anos, cada vez mais as mulheres dominam um espaço que antes não era visto, porém as desigualdades ainda são muitas, e predominam em todos os setores. Diante disso, a pesquisa busca verificar como se distribuem os empregos formais por gêneros entre os setores produtivos do país e dado aquele que detém o melhor desempenho verificar como se desenvolve a alocaçáo do mesmo entre os anos de 2002 e 2018, utilizando para isso o quociente locacional, o coeficiente de localização, o coeficiente de redistribuição setorial e o método de shift-share. Verifica-se que as regiōes que mais possuem mulheres em empregos formais é a regiáo sudeste e sul e o setor de serviços é o setor que mais emprega pessoas do sexo feminino de maneira formal, prevalecendo no setor uma desvantagem competitiva não especializada.
\end{abstract}

Palavras-chave: Serviços; feminino; masculino; diferenças.

\section{CONCENTRATION OF SECTORIAL JOBS IN BRAZILIAN MICRO- REGIONS: AN ANALYSIS BETWEEN GENDERS FOR THE YEARS 2002 TO 2018, WITH EMPHASIS ON THE FEMALE LABOR MARKET}

\begin{abstract}
The participation of women in the labor market has grown over the years, more and more women dominate a space that was not previously seen, but inequalities are still many, and they predominate in all sectors. Therefore, the research seeks to verify how formal jobs are distributed by gender among the productive sectors of the country and given the one that has the best performance, verify how the allocation of the same develops between the years 2002-2018, using the quotient for this. location, the location coefficient, the sectorial redistribution coefficient and the shift-share method. It appears that the regions that have more women in formal jobs is the southeastern and southern regions and the service sector is the sector that most employs women in a formal manner, with a non-specialized competitive disadvantage prevailing in the sector.
\end{abstract}

Keywords: Services; female; male; diferences.

1 Mestranda do Programa de Pós-Graduação em Economia da Universidade Estadual de Ponta Grossa. 


\section{INTRODUÇÁO}

A participaçáo das mulheres no mercado de trabalho vem aumentando ao longo do tempo. Entre os anos de 2004 e 2014 houve aumento da participação das mulheres na contribuiçáo da renda familiar, cujo setor com maior facilidade de entrada foi o setor de serviços, demandando significativa quantidade de mão de obra feminina (COTRIM; TEIXEIRA; PRONI, 2020).

Muitos fatores implicam na decisão de uma mulher entrar ou não no mercado de trabalho, dos quais se elencam as barreiras culturais, institucionais e pessoais, sendo estas últimas decisivas quando muitas vezes se ponderam a maternidade, o casamento e os afazeres domésticos, etc. (SOARES; IZAKI, 2002).

Algumas características sobre a ocupação da mulher devem ser observadas. Em 2016 no Brasil, as mulheres destinaram em média cerca de 7,6 horas a mais por semana para os afazeres domésticos, em relação aos homens. A diferença entre o tempo dedicado para os afazeres domésticos é ainda maior, para mulheres que residem na região nordeste ou são negras. Na ocupaçâo de cargos públicos, as mulheres representavam cerca de 10,7\% dos assentos da Câmara dos Deputados em 2017, e em cargos gerenciais, o percentual sobe para 37,8\% (IBGE, 2018).

Em relação ao acesso à educação, em 2000 a proporção de mulheres com curso superior completo era de 7\%, enquanto os homens 6,53\% (IBGE, 2010). No ano de 2016, a proporção de mulheres com superior completo no país subiu para 16,9\%, e 13,5\% para os homens (IBGE, 2018). A taxa de fecundidade das mulheres e meninas entre 15 e 19 anos, tem o maior valor na regiáo do nordeste sendo de $85,1 \%$ a cada mil mulheres e o menor valor na regiáo sul com 45,6\% a cada mil mulheres. (IBGE, 2018).

A disponibilidade do tempo, portanto, torna-se um dos principais determinantes na oferta feminina de trabalho. Desse modo, verifica-se que o maior percentual das vagas dos empregos formais femininos apresentam características em sua grande maioria de tempo parcial. No Brasil em 2016, 28,2\% das mulheres empregadas formalmente eram de contratos parciais (IBGE, 2018). E em relação ao rendimento médio, as mulheres recebem menos que os homens em média, porém existem profissóes que não geram essa discriminação como é o caso de professores universitários.

Diante desse cenário em que as mulheres vêm adquirindo espaço na economia e na sociedade, apesar das desigualdades, uma questão relevante é verificar qual setor mais emprega mulheres e como está distribuído, possui especialização? Assim, o objetivo da presente pesquisa é identificar o padrão de localização do número de empregos dividido por gênero de acordo com os oito setores divulgados pelo IBGE, entre as microrregióes brasileiras no período que compreende 2002 a 2018. Dado isso, especificamente, pretende-se analisar dentro daquele setor mais concentrado, ou com maior representatividade econômica, a comparação da quantidade de empregos distribuídos entre as mulheres e homens.

Estudos sobre diferenças de empregos por gênero são comuns na literatura nacional e internacional, tais como Bruschini (1994), Scorzafave e Menezes Filho (2001), Probst e Ramos (2003), Costa (2007), Leone e Baltar (2008), kon (2012), Sousa e Guedes (2016) e Verick (2018). 
O trabalho está dividido em cinco seções, sendo esta primeira a introdução; a segunda traz uma breve revisão da literatura; a terceira apresenta a metodologia empregada no desenvolvimento da pesquisa; a quarta aborda os resultados e discussão e, por fim, na quinta seção apresenta as consideraçōes finais.

\section{REVISÁO DA LITERATURA}

Após os anos 70, muitos estudos foram desenvolvidos sobre o mercado de trabalho feminino, sendo que nesse período, as mulheres ganhavam cada vez mais destaque no desenvolvimento das atividades que geravam rendas, com maior participação ativa na economia, ao mesmo tempo em que movimentos sociais como o feminismo ganhavam força (BRUSCHINI, 1994).

$\mathrm{Na}$ literatura, podem-se elencar diversas pesquisas que tratam do tema "Mercado de trabalho por gênero", como é o caso do trabalho de Scorzafave e Menezes Filho (2001) que analisa a evolução e alguns determinantes do mercado de trabalho feminino entre os anos de 1982 e 1997 no Brasil. Os autores utilizam um modelo Probit, com algumas variáveis de controle, como: idade, educação, chefe de família ou não, casada ou não, renda, número de filhos pequenos, número de adultos residentes, além do uso de dummys para diferenciar as regiôes. O resultado revela de um lado, que mulheres com nível de instrução de 1 a 11 anos de estudos, aumentaram sua participação na força de trabalho, enquanto para as mulheres com um alto nível de estudo, as diferenças de evolução na participação na força de trabalho são semelhantes às dos homens. Concluiu-se que educação, idade e casamento são fatores importantes na evolução da participaçáo das mulheres no mercado de trabalho.

Na pesquisa realizada por Probst e Ramos (2003), verificou-se a evolução da participação da mulher na atividade econômica brasileira, por meio de um antecedente histórico do mercado de trabalho, nos quais apontam que no ano de 2000, as mulheres representavam cerca de $41 \%$ da força de trabalho no Brasil e eram remuneradas em cerca de $30 \%$ a menos que os homens, para a mesma função. Para faixas salariais de remuneraçáo superiores a 20 salários mínimos, apenas 19,3\% eram mulheres, isso mostra que apesar das mulheres estarem ocupando cada vez mais um lugar de destaque na sociedade, prevalece ainda muitas diferenças, onde a principal característica é a desigualdade da remuneraçáo salarial.

O trabalho de Costa (2007) buscou identificar os determinantes da participação feminina no mercado de trabalho brasileiro, utilizando-se dados da Pesquisa Nacional de Amostras por Domicílio (PNAD) de 2005, por meio de um modelo Probit, com a utilização de algumas variáveis de controle: raça, estado civil, realização de afazeres domésticos e outras. Estimaram-se dois modelos para fins de comparação, um para mulheres e outro para os homens, com a posterior análise dos efeitos que uma creche apresenta sobre as escolhas de uma atividade de trabalho, bem como os efeitos da interação de renda não laboral e a presença de filhos. Conclui-se que devido ao maior tempo dedicado aos afazeres domésticos, as mulheres tendem a possuir um salário de reserva maior que dos homens. A educação afeta positivamente a decisão da mulher de entrar no mercado de trabalho, a presença de filhos tem um efeito negativo e a presença de creches afeta de maneira positiva a oferta de trabalho da mulher. 
Leone e Baltar (2008) fazem uma avaliação da participação da mulher na recuperação do mercado de trabalho brasileiro, dividindo-o em mercado de trabalho por conta-alheia ${ }^{2}$ e mercado de trabalho por conta própria ${ }^{3}$, utilizando dados da PNAD entre os anos de 2004 e 2006. Verificou-se que o crescimento e o fortalecimento das mulheres na atividade econômica ocorrem de maneira lenta. Além disso, no mercado de trabalho por conta-alheia, o desemprego das mulheres diminuiu. Ou seja, o grau de formalizaçáo do emprego das mulheres é maior do que dos homens, porém ainda assim o desemprego é maior entre as mulheres, enquanto grande parte da renda advinda de remuneraçóes salarias femininas ainda derivam de trabalhos domésticos. Já no trabalho por conta-própria, os homens são a grande maioria entre empregadores e trabalhadores autônomos e, por fim, as diferenças salariais se apresentaram maiores conforme maior o nível de instrução.

No trabalho de Kon (2012) foi realizada a análise dos empregos por gênero para o mercado informal entre os anos de 1999 e 2005, para isso dividiram-se os empregos entre empregos formais e informais por categoria ${ }^{4}$, verificando como se distribuía os empregos entre homens e mulheres para cada categoria escolhida entre aqueles informais. $\mathrm{O}$ resultado revelou que as desigualdades entre os gêneros no mercado de trabalho informal são significativas, porém ao longo dos anos, as mulheres aumentam a participaçáo dentre os trabalhadores, pelo fato da transformação do conjunto social das famílias, em que em muitos casos, as mulheres passam a ser provedoras da renda da família.

Sousa e Guedes (2016) realizaram uma análise descritiva da divisão do trabalho por sexo, utilizando dados da PNAD dos anos de 2004 e 2014. Os autores encontraram o resultado que mostra as mulheres restritas ao trabalho doméstico, apesar do cenário de mudança ao longo do tempo, pois em 2014, cerca de 58\% das mulheres compunham a população economicamente ativa e dentre as regióes, os autores mencionam que existe pouca heterogeneidade da divisão do trabalho feminino.

Verick (2018) verificou a participaçáo e desenvolvimento da força de trabalho feminina, em que o autor aponta grandes diferenças entre as remuneraçóes das mulheres e homens. Além disso, o sexo feminino apresenta maior tendência de execuçáo de trabalho nas funçóes menos protegidas, como é o caso do trabalho doméstico que tende a acentuar as desigualdades entre homens e mulheres no mercado de trabalho. Desse modo, evidencia-se que as desigualdades entre empregos por gênero, embora venham diminuindo ao longo do tempo, ainda sáo um fator preponderante na sociedade, pois o cenário muda com o passar do tempo, no entanto, essas mudanças tem ocorrido lentamente, o que levanta diversas questốes que podem ser analisadas.

2 Abrange os empregados de estabelecimento, o serviço doméstico remunerado e os desempregados.

3 Trabalhadores autônomos, membros de suas famílias que trabalham sem remuneração, empregadores e trabalhadores na produção agrícola para consumo próprio e na autoconstrução.

4 Categoria de emprego, idade, escolaridade, tempo de permanência no emprego, rendimento médio, motivo para entrada no setor informal e jornada de trabalho. 
Considerando o que foi mencionado acima, o objetivo da presente pesquisa é identificar o padrão de localizaçáo do número de empregos dividido por gênero de acordo com os oito setores divulgados pelo IBGE, entre as microrregióes brasileiras no período que compreende 2002 e 2018. Dado isso, especificamente, pretende-se analisar dentro daquele setor mais concentrado, ou com maior representatividade econômica, a comparaçáo da quantidade de empregos distribuídos entre as mulheres e homens.

\section{METODOLOGIA}

Ao considerar que cada região apresenta estrutura produtiva bastante diferenciada, uma vez que as atividades náo se distribuem espacialmente de maneira uniforme, tendo como consequência a tendência de formaçáo de padrōes de localização, ou seja, as características específicas de cada regiáo exercem influência entre os setores das atividades econômicas (DELGADO; GODINHO, 2002). Ao observar esses padrōes de localização, pode-se afirmar que existem padróes específicos para cada setor, com a existência de características que predominam entre os postos de trabalho, ou seja, os postos de trabalhos e a concentração de empregos podem estar relacionados à localidade em que se encontram, já que cada regiāo apresenta composição econômica diferenciada.

Portanto, com esse intuito buscaram-se metodologias para avaliar a concentração dos empregos, considerando que houve alteração da composição dos postos de trabalho formal ao longo do tempo e quais padróes seguiram os empregos femininos e masculinos. A seguir há uma breve revisão dos métodos empregados.

\section{1 ÍNDICES DE CONCENTRAÇÁO}

\subsubsection{Quociente locacional $\left(Q L_{E}\right)$}

O quociente locacional é um índice utilizado para observar se prevalece algum padrão de concentração relativa, da variável básica do setor de referência entre as regiôes, ele pode ser encontrado pela equaçáo abaixo:

$$
\mathrm{QL}_{\mathrm{E}}=\frac{E_{i j} / E_{j}}{E_{i} / E}
$$

Onde $E_{i j}$ é o número de empregos no setor j da regiáo i; $E_{j}$ é o total do número de empregos do setor $\mathrm{j}$ de todas as regióes; $E_{i}$ é o emprego em todos os setores da regiáo i; $E$ é o total do número de empregos em todos os setores e de todas as regióes (HADDAD, 1989).

A variável básica utilizada para elaboração desse trabalho foi o número de empregos. Assim, quanto maior for o valor do Quociente Locacional, maior será a concentração da variável naquele espaço, isso significa que a regiāo é relativamente mais importante naquele setor em termos nacionais (HADDAD, 1989; DELGADO; GODINHO, 2002). 


\subsubsection{Coeficiente de Localizaçáo $\left(C L_{k}\right)$}

Esse coeficiente indica o grau de semelhança ou de disparidade entre o padrão de localização do setor analisado, em relação ao agregado de referência. Com isso é possível analisar a tendência de concentração relativa de uma atividade entre as regiôes, e influenciar políticas de diversificação regional (HADDAD, 1989).

Para esse trabalho ele é empregado com o intuito de verificar se os empregos do setor que se apresentou mais concentrado apresentam, alguma característica de concentração relativa entre as regióes. O Coeficiente de Localização pode ser encontrado utilizando a equação 2 .

$$
C L_{k}=\frac{1}{2} \sum_{i=1}^{1}\left|\frac{E_{i j}}{E_{j}}-\frac{E_{i}}{E}\right|
$$

Onde $E_{i j}$ é o valor do emprego no setor j da regiáo i, $E_{j}$ é o valor total do emprego para o setor; $E_{i}$ é o valor total da variável na regiáo e $E$ é valor total do emprego no país. Seu valor se situa entre zero e um, e quanto mais próximo de zero for seu resultado, mais próximo o padrão de localização da atividade observada está do modelo de referência. Portanto, isso significa afirmar que não se evidencia uma tendência à concentração relativa da atividade no espaço em análise (PIACENTI et al., 2012).

\subsubsection{Coeficiente de redistribuiçáo setorial $\left(\mathrm{C} R_{k}\right)$}

Esse coeficiente é utilizado para verificar a distribuição percentual do emprego de um mesmo setor entre dois períodos de tempo. Com isso busca-se observar ao longo do tempo se existe um padrão de concentraçáo ou de dispersão espacial da variável (HADDAD, 1989). Seu uso nessa pesquisa será a fim de detectar se houve no período de análise concentraçáo ou dispersão dos empregos por gênero para o setor mais concentrado. Assim, pode-se obter o $C R_{k}$ pela equação 3 .

$$
\mathrm{CR}_{\mathrm{K}}=\frac{\sum_{\mathrm{j}}\left(\left|\left(\frac{\mathrm{E}_{\mathrm{ij}}^{1}}{\mathrm{E}_{\mathrm{it}}^{1}}\right)-\left(\frac{\mathrm{E}_{\mathrm{ij}}^{0}}{\mathrm{E}_{\mathrm{it}}^{\mathrm{O}}}\right)\right|\right)}{2}
$$

Onde $E_{i j}^{1}$ é número de empregos do setor j na região i no ano final; $E_{i t}^{1}$ é o emprego total da regiâo i no ano final; $E_{i j}^{0}$ é numero de empregos do setor j na região i no ano inicial; $E_{i t}^{0}$ é o emprego total da regiáo i no ano inicial. $\mathrm{CR}_{\mathrm{K}}$ próximo de zero demonstra que não ocorreram mudanças significativas no padrão espacial da localizaçáo do setor i entre os dois períodos. 


\subsection{MÉTODO DIFERENCIAL E ESTRUTURAL OU SHIFT-SHARE}

O método diferencial-estrutural ou shift-share demonstra o padrão de crescimento de uma variável básica entre as regióes em relação ao país (PIACENTI; ALVES; LIMA, 2008), ou seja, a técnica do shift-share buscar evidenciar as causas do crescimento heterogêneo entre as regiōes em um dado período de tempo (ESTEBAN MARQUILLAS, 1972). O uso para essa pesquisa visa demonstrar como estáo distribuídos os padróes de alocaçóes dos empregos por gênero no setor definido como o mais concentrado, verificando as disposiçóes das vantagens e das especializaçóes.

Como mencionado, a variável básica utilizada é o número de empregos, assim, o emprego cresce de maneira diferente em cada regiáo e em cada setor, isso se dá pelas diferenças estruturais que existem no dinamismo de cada economia. Assim o método diferencialestrutural busca mostrar a diferença entre as forças que contribuem no crescimento regional (HADDAD, 1989). Pode-se observar a variação e o deslocamento do número de empregos no período analisado entre os setores de acordo com a equaçáo 4 com esse método.

$$
\sum_{\mathrm{i}} \mathrm{E}_{\mathrm{IJ}}^{1}-\sum_{\mathrm{i}} \mathrm{E}_{\mathrm{IJ}}^{0}=\mathrm{R}_{\mathrm{J}}+\mathrm{P}_{\mathrm{J}}+\mathrm{D}_{\mathrm{J}}
$$

Onde o lado esquerdo da equaçáo demonstra o crescimento regional, ou seja, o crescimento para cada regiâo entre o período inicial e final, que é composto pela variaçáo regional, à variação estrutural ou proporcional e a variação diferencial (HADDAD, 1989).

Dessa forma, o método do shift-share apresenta o padrão e a fonte de crescimento setorial e regional, sendo dividida em três etapas a análise, como mostrado na equação (4), com intuito de analisar a parcela estrutural, regional e diferencial separadamente (PIACENTI

et al., 2012). Isto é, o termo $R_{J}$ capta a mudança regional que corresponde à alteraçáo da variável de estudo na regiáo j, que teria ocorrido se essa regiáo tivesse apresentado um crescimento na mesma taxa do crescimento da variável de estudo na região de referência, que geralmente é o país, no mesmo período (HADDAD, 1989).

$$
\mathrm{R}_{\mathrm{j}}=\sum_{\mathrm{i}} \mathrm{E}_{\mathrm{ij}}^{0}\left(\mathrm{r}_{\mathrm{tt}}-1\right)
$$

$$
\text { Onde: } \mathrm{r}_{\mathrm{tt}}=\sum_{\mathrm{i}} \sum_{\mathrm{j}} \mathrm{E}_{\mathrm{ij}}^{1} / \sum_{\mathrm{i}} \sum_{\mathrm{j}} \mathrm{E}_{\mathrm{ij}}^{0}
$$

A equação (6) refere-se à variação estrutural ou proporcional $\left(P_{j}\right)$ que corresponde à parcela adicional de variaçáo da variável de estudo na regiáo $\mathrm{j}$, que acontece da composiçáo da sua estrutura produtiva ser mais ou menos dinâmica na regiáo de referência. Ou seja, representa a composição dos setores economicamente dinâmicos sendo que um resultado positivo indica que a regiáo se especializou em setores que possuem altas taxas de crescimento (HADDAD, 1989). 


$$
P_{j}=\sum_{i} E_{i j}^{0}\left(r_{i t}-r_{t t}\right)
$$

\section{Onde: $r_{i t}=\sum_{j} E_{i j}^{1} / \sum_{j} E_{i j}^{0}$}

Por fim tem-se a variação diferencial $\left(D_{j}\right)$ que segundo Piacenti et al (2012) reflete-se o dinamismo que cada setor apresenta dentro da regiáo. Ou seja, as vantagens ou desvantagens locacionais que fazem com que determinado setor possa crescer mais ou menos rápido nessa região do que na região tida como referência, um $D_{j}$ positivo significa que há presença de setores mais especializados nas regiôes, equação (7).

$$
D_{j}=\sum_{i} E_{i j}^{0}\left(r_{i j}-r_{i t}\right)
$$

Onde: $r_{i j}=E_{i j}^{1} / E_{i j}^{0}$

No entanto, surgiram várias críticas ao método em relação ao componente do dinamismo de cada setor, em que se verifica que tal desempenho não é somente resultado das vantagens dinâmicas do setor, mas também da especialização dos empregadores regionais nessa atividade. Ao considerar isso, emprega-se o método disposto por Esteban Marquillas em 1972, com a inclusão do chamado emprego homotético definido na equação (8) como:

$$
\sum_{\mathrm{i}} \mathrm{E}_{\mathrm{ij}}^{0^{\prime}}=\mathrm{E}_{\mathrm{it}}\left(\frac{\mathrm{E}_{\mathrm{ti}}}{\mathrm{E}_{\mathrm{tt}}}\right)
$$

Assim ao reescrever a equação 5 da seguinte maneira, tem-se:

$$
\sum_{\mathrm{i}} \mathrm{E}_{\mathrm{IJ}}^{1}-\sum_{\mathrm{i}} \mathrm{E}_{\mathrm{IJ}}^{0}=\mathrm{R}_{\mathrm{J}}+\mathrm{P}_{\mathrm{J}}+\mathrm{D}_{\mathrm{J}}+\mathrm{A}_{\mathrm{J}}
$$

Onde agora se define na equação 10

$$
\mathrm{D}_{\mathrm{j}}=\sum_{\mathrm{i}} \mathrm{E}_{\mathrm{ij}}^{0 \prime}\left(\mathrm{r}_{\mathrm{ij}}-\mathrm{r}_{\mathrm{it}}\right)
$$

E $\mathrm{A}_{i j}$ é dado por

$$
A_{i j}=\left(\sum_{i} E_{i j}^{0}-\sum_{i} E_{i j}^{0 \prime}\right)\left(r_{i j}-r_{i t}\right)
$$

Quando o valor de $A_{i j}>0$, a regiáo é considerada especializada, enquanto se $A_{i j}<0$, a regiâo não apresenta vantagens sobre as demais (MARQUILLAS, 1972). No Quadro 1 se encontra as tipologias para a análise do método. 
Quadro 1: Tipologia dos efeitos alocação

\begin{tabular}{|c|c|c|c|}
\hline \multirow[b]{2}{*}{ Alternativas } & \multirow[b]{2}{*}{$\begin{array}{l}\text { Efeito } \\
\text { alocação } \\
(A i j)\end{array}$} & \multicolumn{2}{|c|}{ Componentes } \\
\hline & & $\begin{array}{l}\text { Especialização } \\
\left(\boldsymbol{E}_{I J}^{0}-\boldsymbol{E}_{i j}^{0^{\prime}}\right)\end{array}$ & $\begin{array}{l}\text { Vantagem } \\
\text { competitiva } \\
\left.e_{i j}-e_{i}\right)\end{array}$ \\
\hline Vantagem competitiva especializada (VCE) & + & + & + \\
\hline $\begin{array}{l}\text { Vantagem competitiva não especializada } \\
\text { (VCNE) }\end{array}$ & - & - & + \\
\hline $\begin{array}{l}\text { Desvantagem competitiva não especializada } \\
\text { (DCNE) }\end{array}$ & + & - & - \\
\hline $\begin{array}{l}\text { Desvantagem competitiva especializada } \\
\text { (DCE) }\end{array}$ & - & + & - \\
\hline
\end{tabular}

Fonte: Haddad e Andrade (1989).

O efeito alocação pode apresentar duas situaçôes: se for positivo tem-se vantagem competitiva especializada, isso significa que a microrregião é especializada no subsetor $i$, assim o emprego está crescendo mais na microrregião do que no país ou desvantagem competitiva não especializada, que significa que a microrregiáo não é especializada no subsetor $i$, e que o número de empregos desse subsetor cresce menos na microrregião do que no país.

Com um efeito alocação negativo tem-se vantagem competitiva não especializada, em que a microrregião não é especializada no subsetor $i$, porém o número de empregos na microrregião cresce mais do que no país ou pode-se ter uma microrregião especializada no subsetor $i$ com o número de empregos crescendo menos na microrregião do que no país que é chamada de desvantagem competitiva especializada (SANTOS; HILGEMBERG, 2018).

Os dados utilizados foram coletados do Ministério do Trabalho e Emprego (MTE), através da Relação Anual de Informaçōes Sociais (RAIS), subdividindo o número de empregos entre 8 setores: Extrativa mineral, indústria de transformação, serviços de indústria de utilidade pública, construção civil, comércio, serviços, administração pública e agropecuária, englobando os subsetores da extrativa vegetal, caça e pesca divididos por sexo.

\section{RESULTADOS E DISCUSSÁO}

\subsection{Análise do mercado de trabalho no Brasil}

Em relaçáo ao mercado de trabalho brasileiro, a Figura 1 mostra que o número de empregos vem apresentando crescimento ao longo do tempo, tanto para o mercado de trabalho feminino, quanto para o mercado de trabalho masculino, revelando a evoluçáo do emprego no Brasil entre 2002 e 2018. 
Figura 1: Evolução do emprego formal no Brasil entre os anos de 2002 e 2018

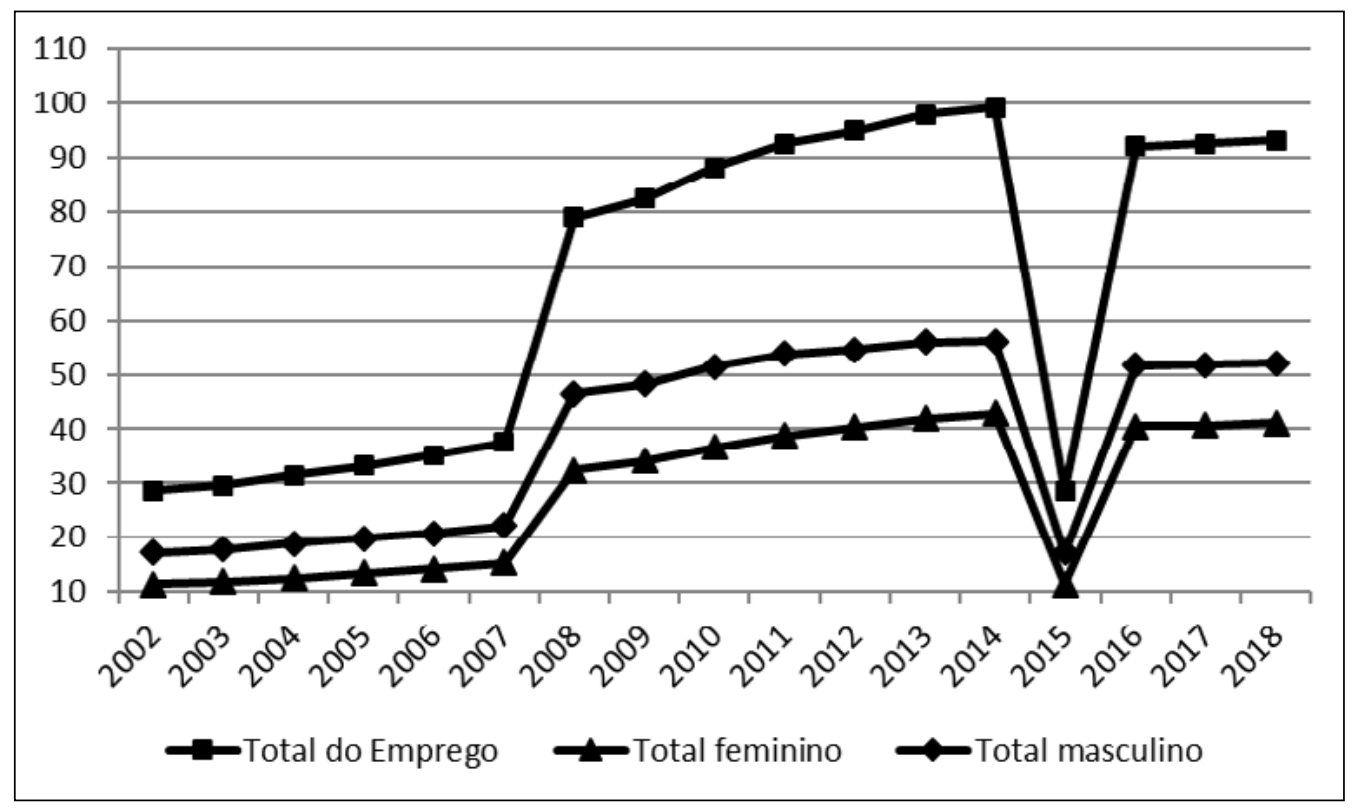

Fonte: Elaboração dos autores com dados da Rais/MTE (2019).

Nota: Valores em milhóes

Ainda na Figura 1, verifica-se que o emprego do país apresentou crescimento no período com uma taxa de variaçáo percentual de $225,13 \%$, em que o emprego feminino mostrou uma taxa de variação percentual de $259,87 \%$ e o emprego masculino de $202,16 \%$. No ano de 2015 observa-se que o número de empregos cai abruptamente, voltando a crescer logo no ano seguinte, alguns fatores que podem explicar essa redução do número de empregos formais na economia brasileira em 2015 é a crise política ocorrida no período e a crise internacional que afetava de maneira negativa a área de produção, originando desemprego (NETO, 2016; MANCEBO, 2017).

As Figuras 2 e 3 mostram a evolução do número de empregos formais em 8 setores da economia: extrativa mineral, indústria de transformação, serviços de indústria e utilidade pública, construção civil, comércio e serviços, administração pública e agropecuária sendo divididos em empregos femininos e empregos masculinos para os anos analisados. 
Figura 2: Evoluçâo do emprego formal feminino por setor no Brasil entre os anos de 2002 e 2018

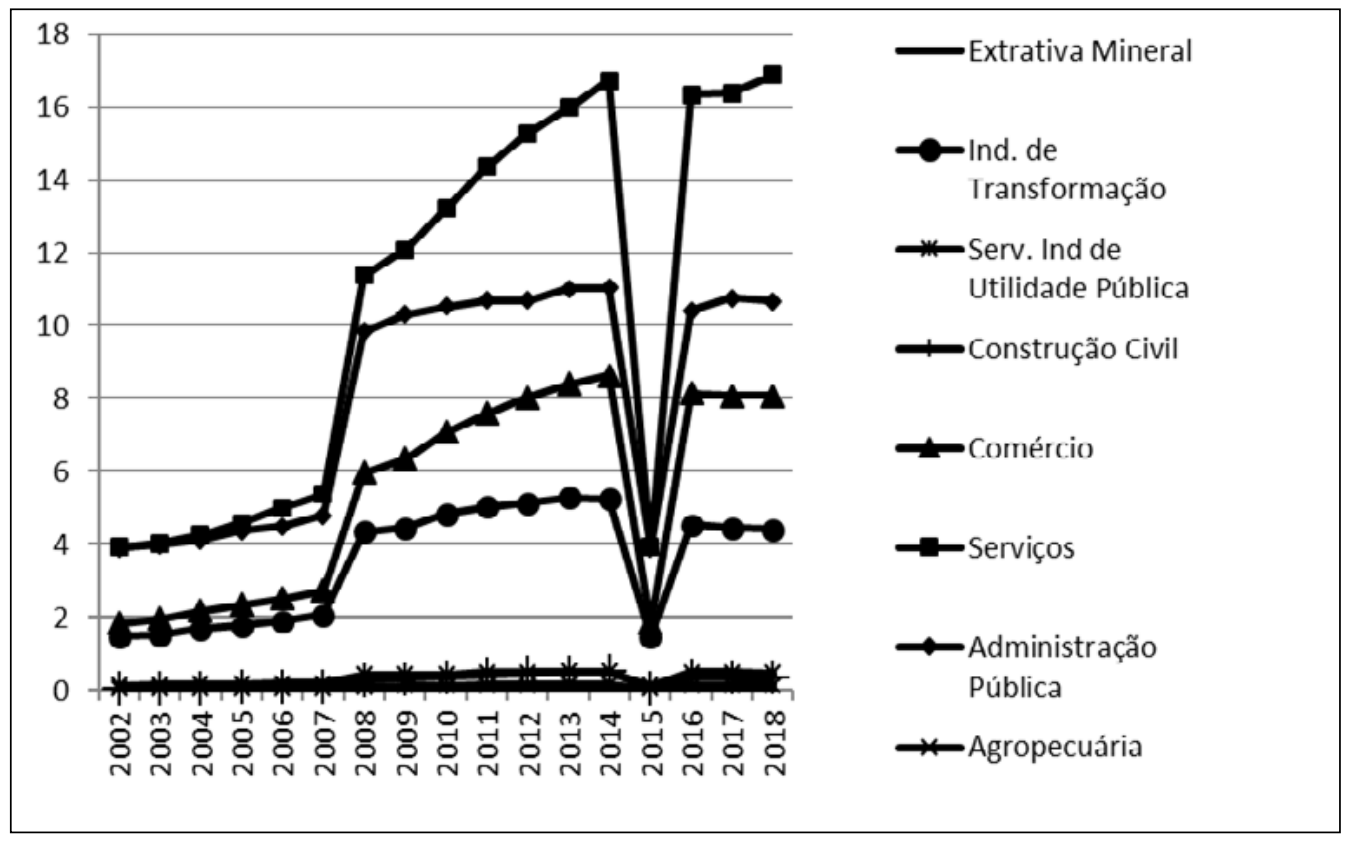

Fonte: Elaboração do autor com dados da Rais/MTE (2019).

Nota: Valores em milhóes. 
Figura 3: Evolução do emprego formal masculino por setor no Brasil entre os anos de 2002 e 2018

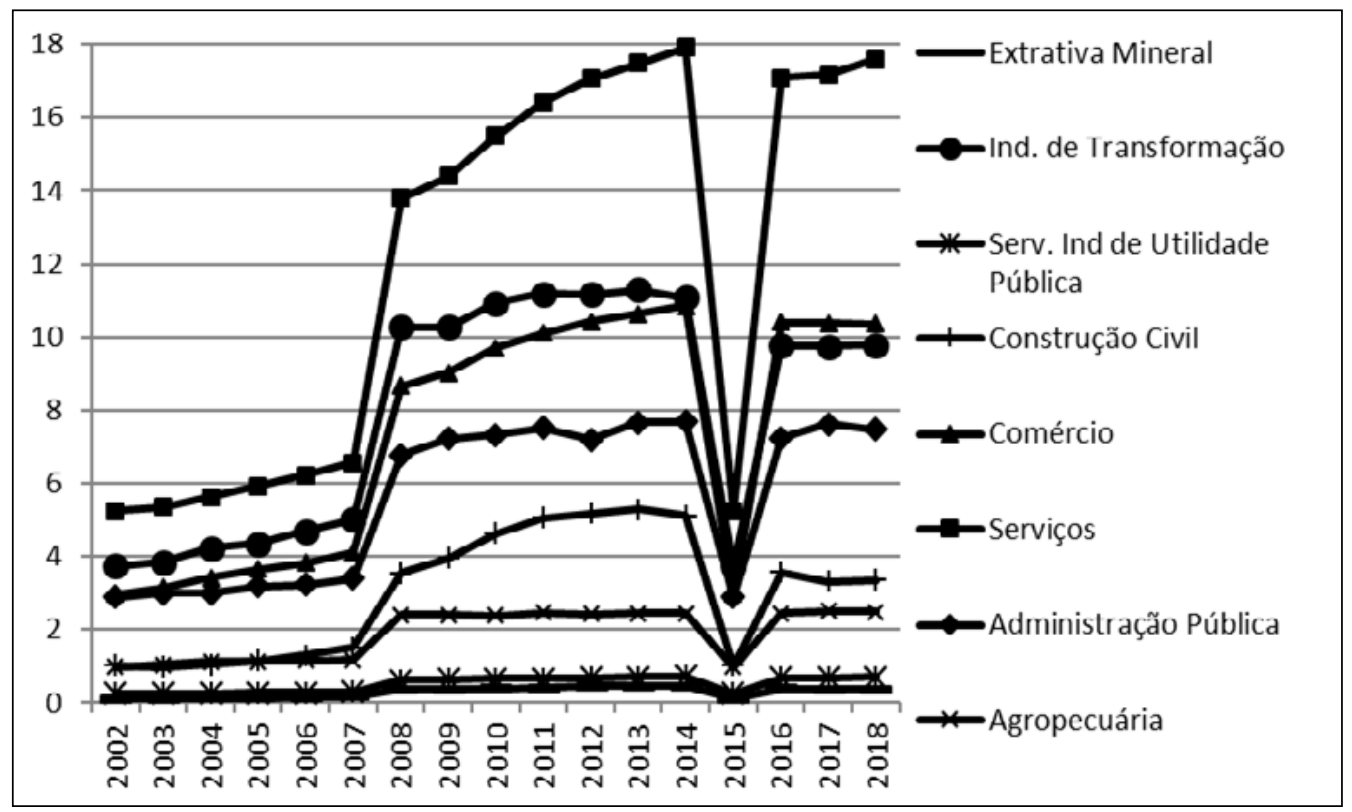

Fonte: Elaboração dos autores com dados da Rais/MTE (2019).

Nota: Valores em milhóes

Especificamente, pode-se verificar que o setor que apresenta o maior número de empregos femininos e masculinos é o setor de serviços, enquanto o menor é o setor da extrativa mineral. Já o segundo maior número de empregos entre as mulheres se encontra no setor de administração pública e para os homens, no setor de indústria de transformação.

O setor de serviços apresenta crescimento superior do emprego formal em relação ao do comércio e da indústria, sendo que um dos fatores que contribui para o forte crescimento desse setor é a globalização de muitos serviços, influenciada pelas inovaçóes tecnológicas (NEGRI et al., 2006).

Como verificado acima, o setor que apresentou a maior quantidade de empregos formais tanto masculinos quanto femininos foi o setor de serviços, dado o destaque que o setor apresentou ao longo do período analisado, os próximos resultados se concentrarão em analisar apenas esse setor.

\subsection{Análises dos resultados do quociente locacional, coeficiente de redistribuiçáo e coeficiente de localização para o setor de serviços}

Ao considerar a relevância do setor de serviços no mercado de trabalho, tanto feminino quanto masculino devido seu significativo crescimento, buscou se identificar os padrôes de concentração desse setor, para cada gênero. Nas Figuras 4 e 5 é possível observar a distribuição espacial do quociente locacional para o setor de serviços entre as microrregióes brasileiras para mulheres e homens. 
Figura 4: Distribuição espacial do quociente locacional do emprego formal feminino no setor de serviços $(2002,2007,2012$ e 2018)

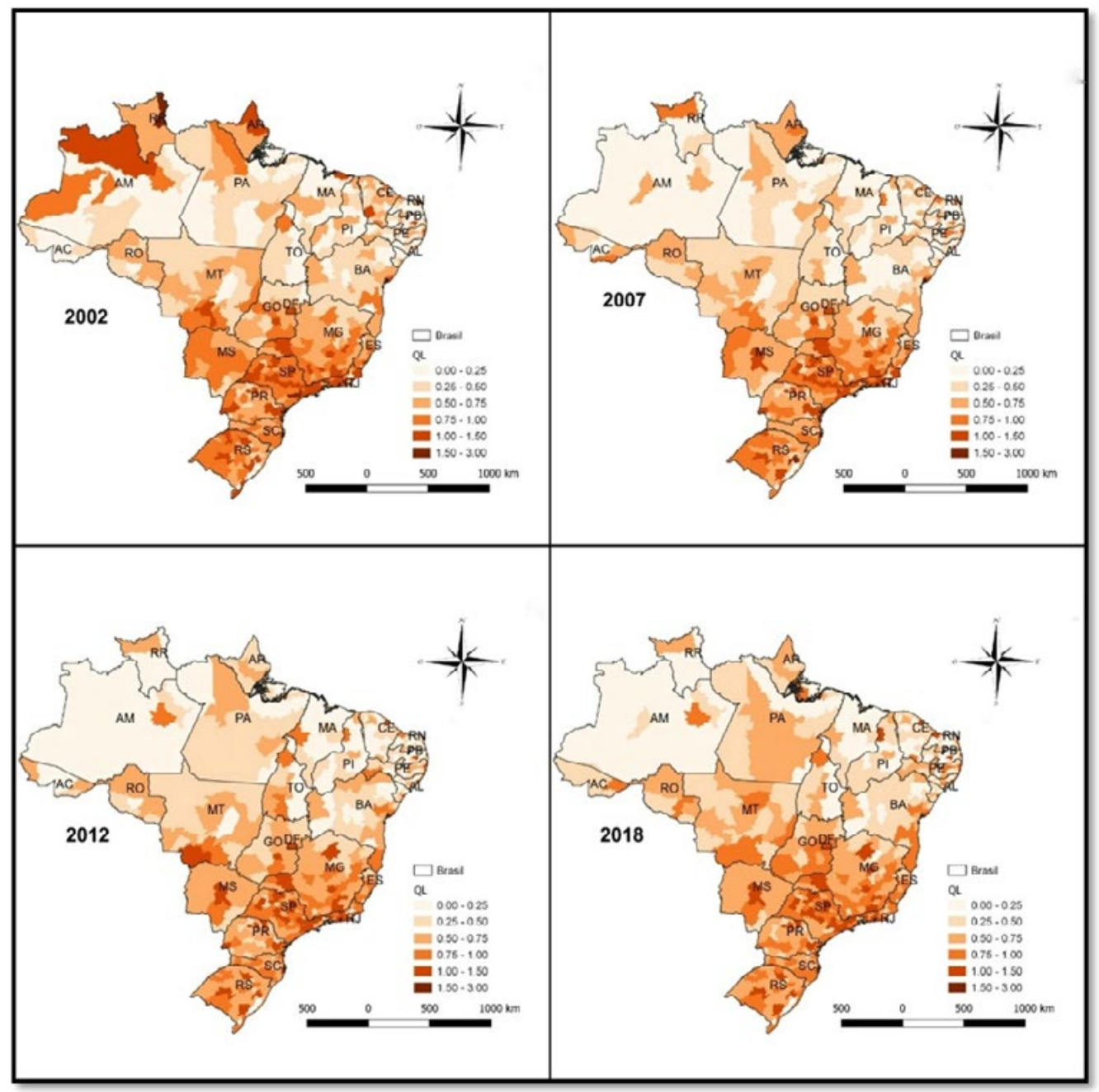

Fonte: Elaboração dos autores com dados: Rais/MTE (2019).

Pela análise, verifica-se que em 2002 (Figura 4) há uma concentração de empregos femininos no setor dos serviços em microrregiões da região Norte, porém essa concentração apresentou queda ao longo dos anos. As regióes que apresentam o maior número de microrregióes com quociente locacional maior, são as regióes sudeste e sul e houve crescimento da concentração do emprego feminino nas microrregióes da região do CentroOeste. 
Figura 5: Distribuição espacial do quociente locacional do emprego formal masculino no setor de serviços $(2002,2007,2012$ e 2018)

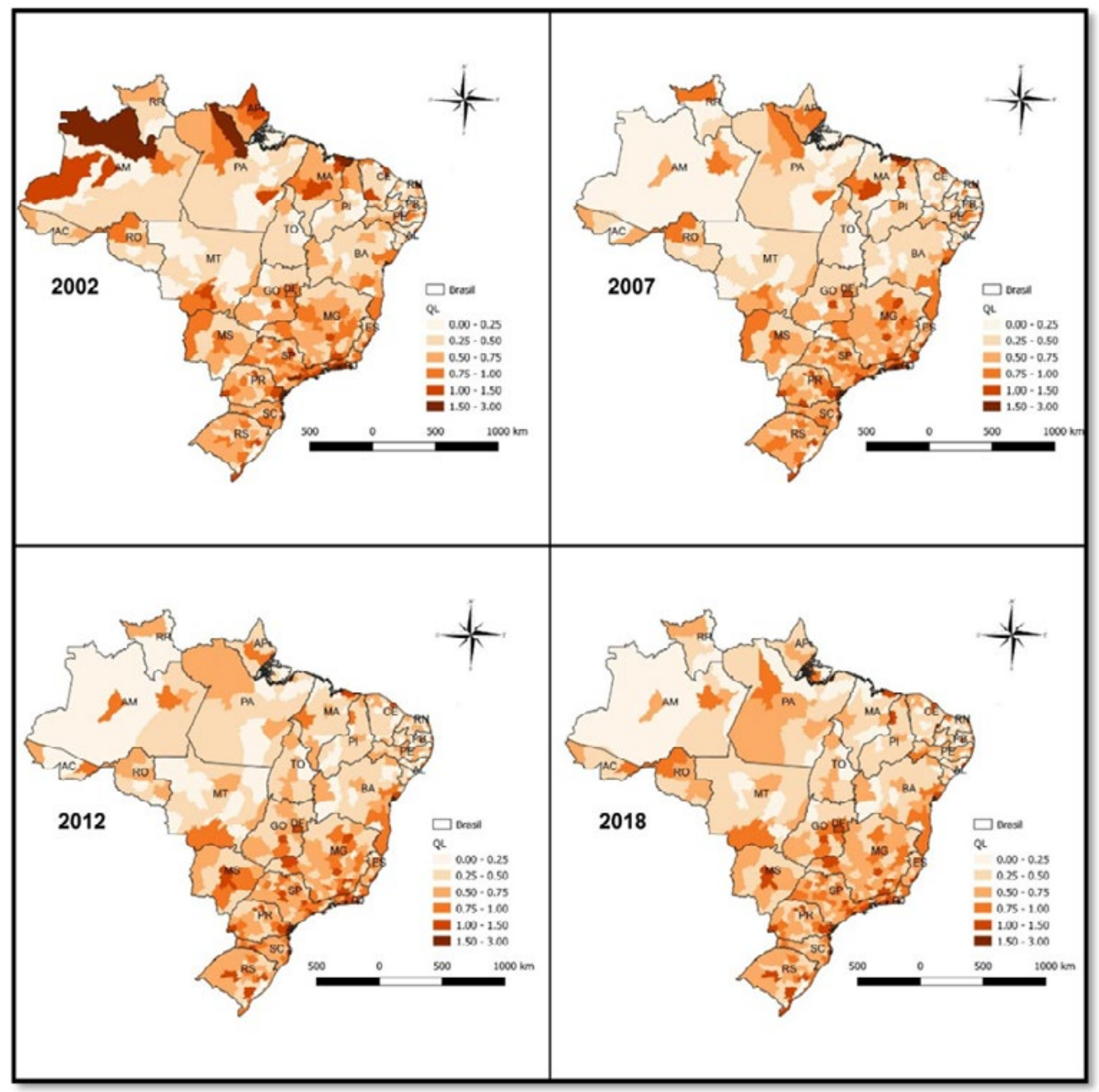

Fonte: Elaboração dos autores com dados da Rais/MTE (2019).

No mercado de trabalho masculino (Figura 5), identifica-se uma concentração de empregos no setor de serviços para algumas microrregiốes da região Norte em 2002, porém em 2018, observa-se que o número de microrregióes apresentando um quociente locacional alto tendeu a diminuir. Uma possível explicação para a concentração de empregos no setor de serviços da região Norte apresentar queda, é que essa regiáo possui um grande número de comércios (SEBRAE, 2015), no entanto ao longo dos anos outras atividades foram melhores desenvolvidas gerando postos de trabalhos, isso cooperou para uma diversificação de trabalho. 
Os resultados são semelhantes aos encontrados por outros autores, como Piacenti, Alves e Lima (2008) que identificaram uma concentração de empregos nos setores de serviços e construção civil para a região norte.

A Figura 6 mostra a distribuição espacial do coeficiente de redistribuição para as microrregióes brasileiras no setor de serviços. Neste coeficiente pode-se observar que prevaleceu algum comportamento de concentração ou de dispersão do emprego feminino e masculino no setor de serviços no período entre 2002 e 2018.

Figura 6: Distribuiçãao espacial do coeficiente de redistribuição para o setor de serviços (2002-2018)

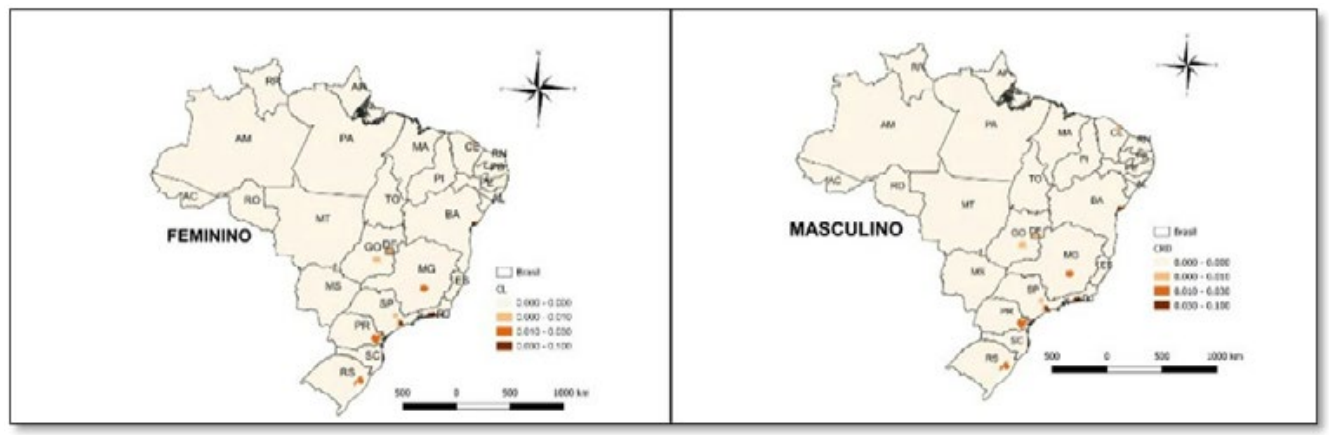

Fonte: Elaboração dos autores com dados da Rais/MTE (2019).

Entre 2002 e 2018, o coeficiente de redistribuição apresenta baixos valores, entre 0 e 0,5 , praticamente em todas as microrregióes, ou seja, o resultado mostra que não houve mudanças significativas nos padróes de localização do emprego do setor de serviços entre as microrregióes, tanto para mulheres quanto para homens. Portanto, pode-se afirmar que os empregos formais no setor de serviços, não apresentam nenhuma alteração significativa para o período analisado. No trabalho de Piacenti, Alves e Lima (2008), o coeficiente de redistribuição é calculado entre os anos de 1985 e 2000 para cinco setores da economia, os resultados apresentaram que os setores de serviços e da agropecuária, apresentaram mudanças significativas em seu padrão espacial de localização para o período de estudo dos autores.

Nessa mesma ótica, o coeficiente de localização apresenta também valores muito próximos de zero para todas as microrregiōes e para todos os anos, isso significa que o emprego tanto feminino quanto masculino está distribuído regionalmente de forma semelhante no conjunto dos demais setores, figura 7 e 8 . 
Figura 7: Distribuição espacial do coeficiente de localização para os empregos femininos do setor de serviços $(2002,2007,2012$ e 2018)

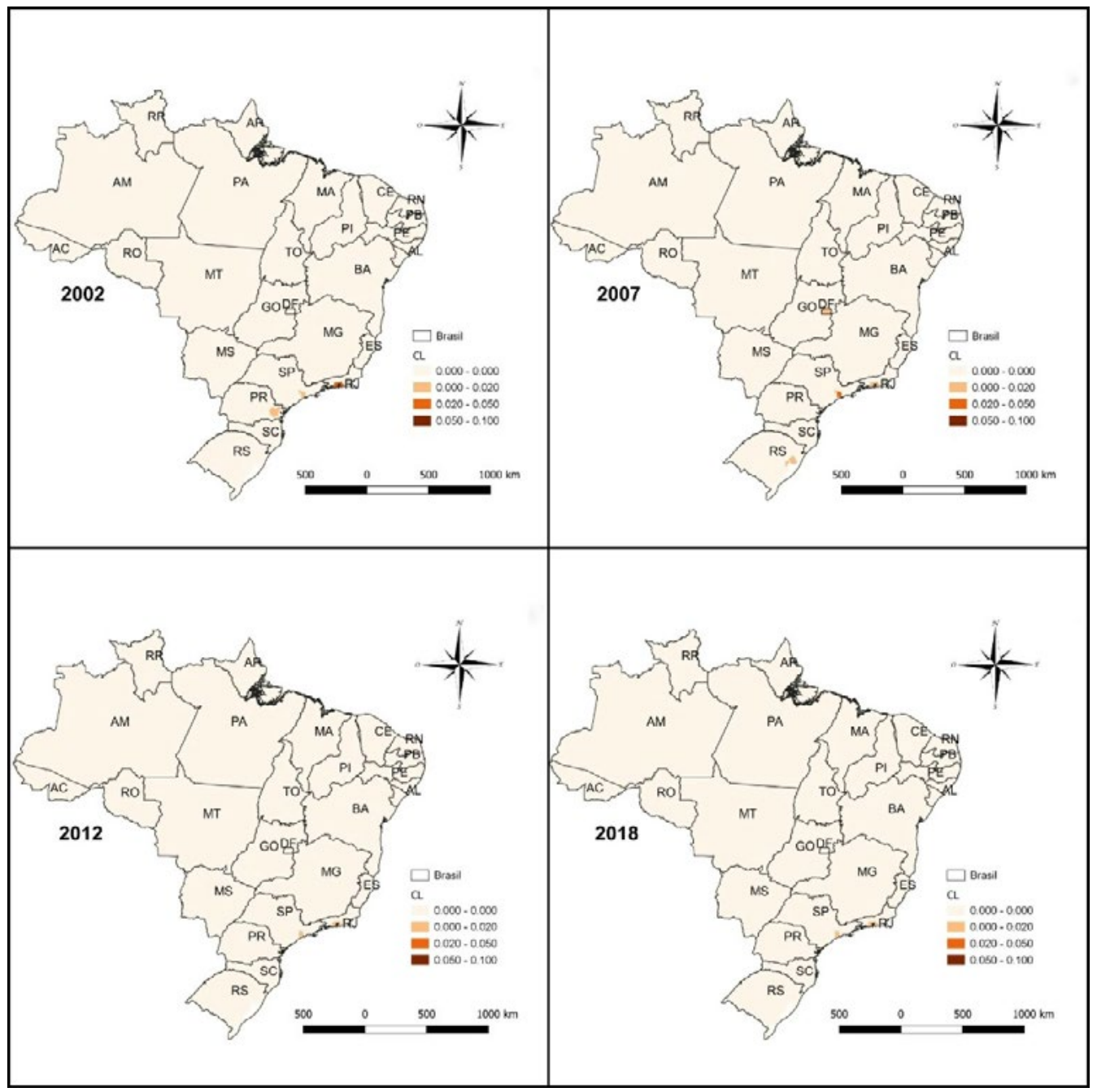

Fonte: Elaboraçáo dos autores com dados da Rais/MTE (2019). 
Figura 8: Distribuição espacial do coeficiente de localização para os empregos masculinos do setor de serviços (2002, 2007, 2012 e 2018)

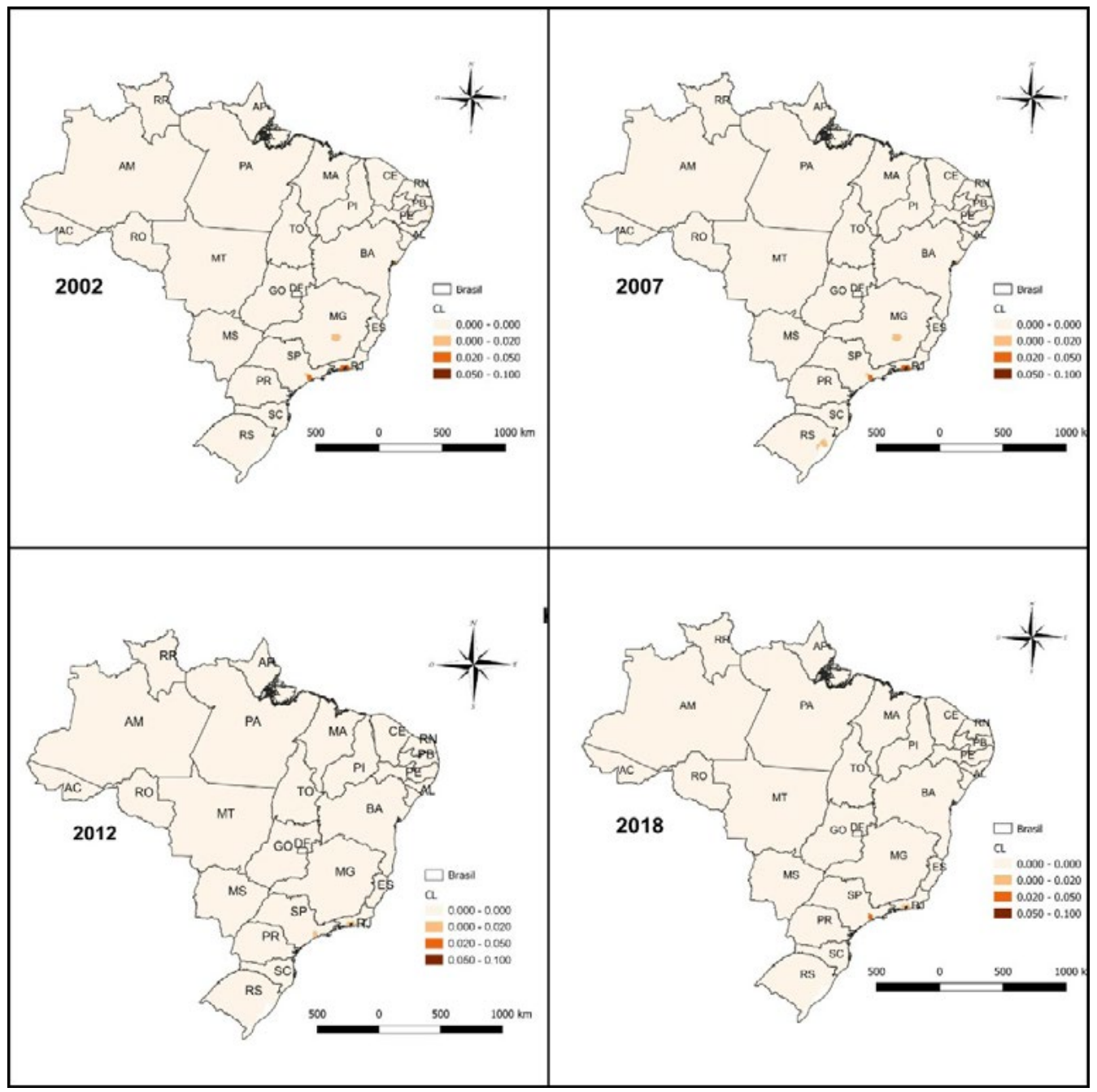

Fonte: Elaboraçáo dos autores com dados da Rais/MTE (2019).

\subsection{Análise do resultado do método shift-share para o setor de serviços}

$\mathrm{Na}$ Figura 8 é possível identificar as tipologias encontradas por meio do método shift-share para o setor de serviços das microrregiôes brasileiras para mulheres e homens. 
Figura 8: Classificação das microrregióes brasileiras para os empregos formais do setor de serviços, seguindo a tipologia do método shift-share para os anos de 2002 a 2018.

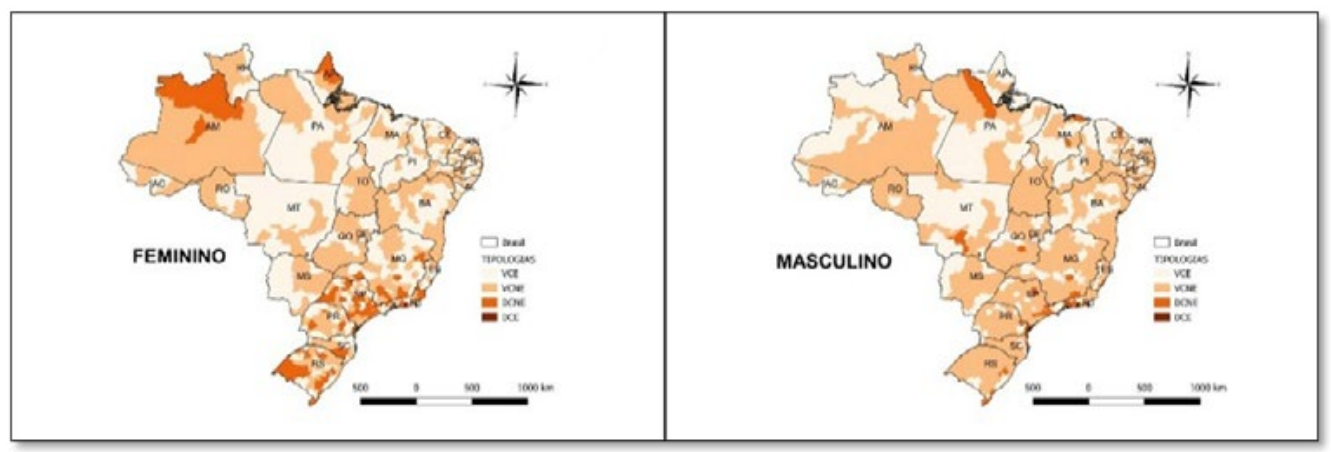

Fonte: Elaboração dos autores com dados da Rais/MTE (2019).

Nota: Versão Esteban-Marquilas (1972).

No setor de serviços, o mercado de trabalho feminino é responsável por aproximadamente $6,98 \%$ das microrregióes do Brasil que apresentam vantagem comparativa especializada nos empregos femininos; cerca de 36,91\% tem vantagem comparativa náo especializada; outras $44,62 \%$ possuem desvantagens comparativas não especializadas e, por fim, cerca de $11,46 \%$ apresentam desvantagem comparativa especializada. Já o mercado de trabalho masculino responde por cerca de $4,12 \%$ das microrregiōes, classificadas com vantagem competitiva especializada; $25,26 \%$ se encontram com vantagem competitiva não especializada; $63,62 \%$ das microrregióes tem desvantagem competitiva não especializada e, finalmente, cerca de 6,98\% possuem desvantagem competitiva especializada.

Em termos regionais, especificamente nas regiōes Sul e Sudeste, o mercado de trabalho feminino apresenta um número maior de microrregióes classificadas como desvantagem competitiva especializada, num total de 64 microrregióes. Ou seja, essas regiōes apresentam especialização no setor de serviços, as atividades estão especializadas nesse setor, no entanto, ao mesmo tempo, possuem um número de empregos que cresce de forma mais lenta do que da economia como um todo. Em contrapartida, ao analisar este segmento para o mercado de trabalho masculino, a grande maioria das microrregióes dessas regióes está classificada como desvantagem competitiva não especializada, o que mostra que não há especialização no setor de serviços e o emprego cresce mais lentamente se comparado ao emprego nacional.

Portanto, pode-se afirmar que o emprego feminino apresenta vantagem competitiva especializada em um número maior de microrregióes brasileiras, das quais 39 microrregióes foram classificadas como VCE, ao passo que para o emprego masculino, quase a metade, cerca de 23 microrregióes. Podemos assim, concluir que as regióes Sul e Sudeste são as localidades que apresentam maior número de microrregióes que se encaixam nessa tipologia. Ou seja, uma região que apresenta VCE é caracterizada por possuir especialização no setor analisado e por ter um número de empregos que cresce de forma mais acelerada que da economia como um todo (SANTOS; HILGEMBERG, 2018; HADDAD; 1989). 
A análise supracitada confirma o que vem ocorrendo na regiáo Sul, uma vez que o emprego formal feminino vem crescendo ao longo dos anos. Por exemplo, o Paraná que gerou em 2019 cerca de 21.302 novos postos de trabalho para as mulheres, isso representa um crescimento de $38,33 \%$ nas vagas de empregos femininos em relação ao ano anterior (AEN/PR, 2020). Entretanto, em 2015 a região Sudeste que corresponde $50 \%$ do emprego e do PIB do país, apresentou um encolhimento dos postos de trabalho, principalmente nos municípios com maior população, em função da crise vivenciada pelo país no período (MATTOS; FERREIRA, 2017).

Por fim, há predominância da vantagem competitiva não especializada nas regióes Norte, Nordeste e Centro Oeste, para o emprego feminino com cerca de 206 microrregióes para esta classificação, enquanto que para os homens, o número cai para 141 microrregiōes, ou seja, essas regiốes apresentam característica de especializaçáo no setor de serviços, no entanto, o número de empregos cresce de maneira mais lenta se comparado ao restante da economia.

\section{CONSIDERAÇÓES FINAIS}

A pesquisa tinha como objetivo identificar o padrão de localização do número de empregos dividido por gênero de acordo com os oito setores divulgados pelo IBGE, entre as microrregióes brasileiras no período que compreende 2002 a 2018. O setor de serviços foi o mais significativo para essa análise e para esse período, desse modo comparou-se a quantidade de empregos distribuídos entre as mulheres e homens empregados nesse setor formalmente. Observou-se que até 2014, o Brasil apresentou uma tendência de crescimento no número de empregos formais observado tanto para os empregos no mercado de trabalho feminino quanto masculino, sendo o setor de serviços que apresentou o maior número de empregos formais e a maior taxa de variação dos empregos formais no período.

Em termos regionais, a regiāo Sul apresentou os maiores números de empregos formais femininos e empregos masculinos, enquanto a regiáo Norte apresentou os menores valores.

Observando os valores do quociente locacional identificou-se concentração dos empregos em algumas microrregióes da região norte, sul e sudeste. Quanto à análise do coeficiente de redistribuição, pode-se afirmar que ao longo dos anos, as microrregiôes apresentaram CRD bem próximo de zero, isso significa que há um padrão de dispersão dos empregos do setor de serviços, ou seja, a concentraçáo para esse setor tendeu a diminuir ao longo dos anos. O coeficiente de localização também apresentou valores baixos identificando a ausência de concentração relativa deste setor no espaço de análise.

Pela análise shift-share ao observar os efeitos de alocação, pode-se afirmar que a grande maioria das microrregióes apresentou desvantagem competitiva não especializada, com maiores números de microrregiōes classificadas como DCNE nos empregos no mercado de trabalho masculino. $\mathrm{O}$ emprego feminino se apresentou com maior valor para vantagem competitiva especializada, apesar desse valor ser baixo em relação as demais classificaçôes. $\mathrm{O}$ que se pode concluir é que quando se trata vantagem competitiva o emprego feminino possui os maiores valores, enquanto para especialização são os empregos masculinos que 
se destacam. Essa diferença entre vantagens e especializaçóes é uma sugestão para futuros trabalhos e levanta a discussão acerca de politicas publicas que busquem a homogeneidade dos empregos, contribuindo para a melhoria das vantagens e espacializaçóes dos empregos totais.

\section{REFERÊNCIAS}

AEN/PR. Agência de Noticias do Paraná. 2020. Disponível em: < http://www.aen.pr.gov. $\mathrm{br} /$ modules/noticias/article.php?storyid=106032\&tit=Contratacao-de-mulheres-cresce3833-no-Parana>. Acesso em 14 de abril de 2020.

BRUSCHINI, C. Trabalho Feminino trajetória de um tema perspectivas para o futuro. Revista Estudos Feministas.1994. v. 2, n. 3, p. 17.

COSTA, J. S. de M. Determinantes da participação feminina no mercado de trabalho brasileiro. Repositório UNB. 2007.

COTRIM, L. R; TEIXEIRA, M. O; PRONI, M. W. Desigualdade de gênero no mercado de trabalho formal no Brasil.2020.

DELGADO, A. P.; GODINHO, I. M. Medidas de localização das actividades e de especialização regional. In: COSTA, J. S. (Coord.). Compêndio de economia regional. Coimbra: APDR. 2002. p.723-742. [Capítulo 20].

ESTEBAN-MARQUILLAS, J. M. Shift-and share analysis revisited. Regional and Urban Economics, 1972 v. 2, p. 249-261.

HADDAD, P. R. Medidas de localização e especialização. In: HADDAD, P. R. (Org.).

Economia regional: teorias e métodos de análise. Fortaleza: BNB. ETENE.1989. cap.4, p.225- 247. [Capítulo 4].

IBGE. Instituto Brasileiro de Geografia e Estatística. 2010. Disponível em: < https://www. ibge.gov.br/apps/snig/v1/?loc=0\&cat=-1,1,2,-2,3,4,48,128,129\&ind=4699>. Acesso em 29 de julho de 2020.

IBGE. Instituto Brasileiro de Geografia e Estatística. Indicadores sociais das mulheres no Brasil. Estudos e Pesquisas-Informaçáo Demográfica e Socioeconômica, (38). 2018

KON, A. A distribuição do trabalho informal no Brasil em uma perspectiva de gênero. Revista Venezolana de Análisis de Coyuntura, 2012. 18(1), 201-229.

LEONE, E. T., BALTAR P. A mulher na recuperação recente do mercado de trabalho brasileiro. Revista Brasileira de Estudos de Populaçáo, 2008. 
MATOS, R; FERREIRA, R. N. Brasil em Crise e o Emprego Formal no Sudeste.

Caminhos de Geografia, 2012. 18(61), 150-164.

MANCEBO, D. Crise político-econômica no Brasil: breve análise da educaçáo superior.

Educação \& Sociedade, 2017. 38(141), 875-892.

MTE/PDET. Ministério do trabalho e emprego. 2019. Disponível em: < http://pdet.mte. gov.br/rais>. Acesso em 22 de setembro de 2019.

DE NEGRI, J. A. O; KUBOTA, L. C. O; SILVA, A. M., KON, A; FREIRE, C. T; MEIRELLES, D; LEMOS, M. B. Estrutura e dinâmica do setor de serviços no Brasil. Repositório IPEA. 2006.

NETO, O. A. A crise política brasileira de 2015-2016: Diagnóstico, sequelas e profilaxia. Relaçóes Internacionais (R: I), 2016. (52), 43-54.

PIACENTI, C. A., ALVES, L. R., DE LIMA, J. F. O perfil locacional do emprego setorial no Brasil. Revista Econômica do nordeste, 2008. 39(3), 482-502.

PIACENTI, C. A., LIMA. J. F., ALVES. L. R., RIPPEL, R. Indicadores de localização, especialização e estrutura regional. In: PIACENTI, C. A., LIMA. J. F (Org.). Análise regional: metodologia e indicadores. Curitiba: Camóes, 2012. cap.3, p.33- 49.

PROBST, E. R., RAMOS, P. A evolução da mulher no mercado de trabalho. Santa Catarina: Instituto Catarinense de Pós-Graduaçáo, 2003. p. 1-8.

SANTOS, C. V., HILGEMBERG, C. M. D. A. T. Emprego formal no setor de serviços nos municípios dos campos gerais do paraná: uma análise para o período 2000-2010.

Planejamento e Políticas Públicas, (51). 2018

SCORZAFAVE, L. G., MENEZES-FILHO, N. A. Participação feminina no mercado de trabalho brasileiro: evolução e determinantes. Repositório IPEA. 2001.

SEBRAE, 2015. Disponível em: <https://www.sebrae.com.br/Sebrae/Portal\%20Sebrae/ Estudos\%20e\%20Pesquisas/Relat\%C3\%B3rio\%20-\%20Regi\%C3\%A3o\%20Norte\%20. pdf >. Acesso em: 23 dez 2019.

SOARES, S; IZAKI, R. S. A participação feminina no mercado de trabalho. Repositório IPEA. 2002.

SOUSA, L. P. D; GUEDES, D. R. A desigual divisão sexual do trabalho: um olhar sobre a última década. Estudos avançados, 2016. 30(87), 123-139.

VERICK, S. Female labor force participation and development. IZA World of Labor. 2018. 